Supplementary Information

\title{
Inkjet printing for manufacturing solid oxide fuel cells
}

Gwon Deok Han ${ }^{a, \dagger}$, Kiho Bae $e^{b, \grave{t}}$, Eun Heui Kang ${ }^{a}$, Hyung Jong Choi ${ }^{a}$, and Joon Hyung Shim ${ }^{a, *}$

${ }^{a}$ School of Mechanical Engineering, Korea University, 145 Anam-ro, Seongbuk-gu, Seoul 02841, Korea

${ }^{b}$ Department of Mechanical Engineering, Stanford University, Stanford, CA, 94305 USA 


\section{Experimental methods and details}

Ceramic ink synthesis Commercially available ceramic powders were used as the raw materials for the SOFCs. A mixture of $40 \mathrm{wt} \%$ of YSZ (TZ-8Y, Tosoh) and $60 \mathrm{wt} \%$ of NiO (Sumitomo) was used as the raw material for the anode functional layer (AFL) ink. YSZ and $\mathrm{Gd}_{0.1} \mathrm{Ce}_{0.9} \mathrm{O}_{2-\delta}$ (GDC, Rhodia) were used as the ink sources for the electrolyte and buffer layers, respectively. These ceramic inks were synthesized based on mixture solvents consisting of water and ethanol. The mass ratios between water and ethanol of the mixture solvents used in the NiO-YSZ, YSZ, and GDC inks were 4:1, 2:1, and 4:1, respectively. The raw powders were dispersed in the solvents premixed with DISPERBYK-2012 (BYK-Chemie GmbH) as the dispersant and 1,5pentanediol (Sigma-Aldrich) as the humectant. Polyvinylpyrrolidone (PVP)-K30 (SigmaAldrich) was added in the GDC ink as the binder. For the cathode layer, $\mathrm{PrBa}_{0.5} \mathrm{Sr}_{0.5} \mathrm{Co}_{1.5} \mathrm{Fe}_{0.5} \mathrm{O}_{5+\delta}$ (PBSCF, Kceracell) was used as the raw material. Considering the reactivity of the PBSCF powder with water molecules, we used a mixture solvent composed of propylene glycol methyl ether (PGME, Sigma-Aldrich) and ethanol (75:25 w:w). For the PBSCF ink, the same dispersant (DISPERBYK-2012) was used, but the humectant was varied to glycerol (Sigma-Aldrich) in respect to the solubility with the changed solvent. Ethyl cellulose (DAEJUNG) was also used in the PBSCF ink as the binder. All the synthesized ceramic inks were ball-milled for $48 \mathrm{~h}$ at $120 \mathrm{rpm}$ using 3,5 , and $10 \mathrm{~mm}$ zirconia beads.

Ink evaluation A particle size analyzer (ELSZ-1000, Otsuka Electronics Co. Ltd.) was used to evaluate the dispersion states of the raw powders in the ceramic inks. The particle size distribution was analyzed based on dynamic light scattering (DLS). To evaluate the dispersion stability, the particle size distributions of the ceramic inks were analyzed on the $8^{\text {th }}$ and $29^{\text {th }}$ day 
after the synthesis. The ink viscosities of the printed SOFC components were measured using a vibrational viscometer (SV-10, A\&D Company). The measurement of surface tensions was performed using a surface tension analyzer (SEO) based on the ring method.

Fabrication of the inkjet-printed SOFC Die-pressed NiO-YSZ (56:44 w:w) pellets were used as the anode support for the fabrication of the inkjet-printed SOFC. A commercial HP inkjet printer (HP Deskjet 1110) with the original HP63 black ink cartridge (F6U62AN) was used for the fabrication of the electrode and electrolyte layers. The price of the HP Deskjet 1110 model was \$29.99, available at the Amazon online site. A $6 \mu \mathrm{m}$ thick NiO-YSZ AFL was printed on the NiO-YSZ pellet with 15 printing scan cycles. To evaluate the minimum thickness of the electrolyte, we performed 1, 2, and 5 printing scan cycles of YSZ. After the deposition of the YSZ electrolyte, the AFL and YSZ electrolyte layers were co-sintered at $1400{ }^{\circ} \mathrm{C}$ for $3 \mathrm{~h}$. The sintering condition was determined through a preliminary test at scanning sintering temperatures of $1300-1400^{\circ} \mathrm{C}$. From the test results, no significant difference was observed in the performance. Meanwhile, the pinholes at the electrolyte and the overall mechanical strength improved with the increase in temperature. These findings were in good agreement with the results reported in the literature. ${ }^{1,2}$ A $0.5 \mu \mathrm{m}$ thick GDC buffer layer was printed on the YSZ electrolyte to prevent the interface reaction between the cathode and electrolyte and then the printed GDC buffer layer was sintered at $1200^{\circ} \mathrm{C}$ for $2 \mathrm{~h}$. An $8 \mu \mathrm{m}$ thick PBSCF cathode layer was inkjet-printed on the GDC buffer layer. The sintering of the PBSCF cathode was performed at $900^{\circ} \mathrm{C}$ for $3 \mathrm{~h}$.

XRD/SEM X-ray diffraction (XRD, Rigaku SmartLab, $\mathrm{Cu} \mathrm{K}_{\alpha}$ radiation) was used to evaluate the crystallinity of the inkjet-printed SOFC. The $2 \theta-\theta$ scanning mode was employed for the XRD characterization of the raw ceramic powders and inkjet-printed SOFC. The microstructure 
of the inkjet-printed SOFC including the thickness and porosity of each component was observed using field-emission scanning electron microscopy (SEM, Hitachi S-4800 and SU-70).

Fuel cell measurements The fuel cell performance of the inkjet-printed SOFC was evaluated using a customized test setup. The $I-V$ characteristics and electrochemical impedance spectroscopy (EIS) were recorded using an electrochemical analyzer (Gamry Reference 3000 Potentiostat/Galvanostat/ZRA). The electrochemical performance of the SOFC was evaluated at the intermediate temperatures of $650,600,550$, and $500{ }^{\circ} \mathrm{C}$. The flow rate of the humidified hydrogen and air $\left(\mathrm{P}_{\mathrm{O}_{2}}=0.2 \mathrm{~atm}\right)$ was set to $150 \mathrm{sccm}$. $\mathrm{Ni}$ and $\mathrm{Au}$ meshes were used as the current collectors for the anode and cathode, respectively. The EIS data were obtained at the frequency range of $10^{6}-0.1 \mathrm{~Hz}$ with an $\mathrm{AC}$ amplitude of $10 \mathrm{mV}$ at cell voltages of the opencircuit condition and $0.75 \mathrm{~V}$. The $I-V$ characteristics were measured in the range of OCV to 0.2 $\mathrm{V}$ using the linear sweep voltammetry method. An equivalent circuit consisting of one resistance and four parallel resistances/constant-phase elements was used to fit the Nyquist plot from the EIS data. The stability of the SOFC was measured using the galvanostatic method with a current density of $111 \mathrm{~mA} \mathrm{~cm}^{-2}$ at $550{ }^{\circ} \mathrm{C}$ for over $110 \mathrm{~h}$. The EIS analysis was performed before and after the stability test. 


\section{Additional data and figures}
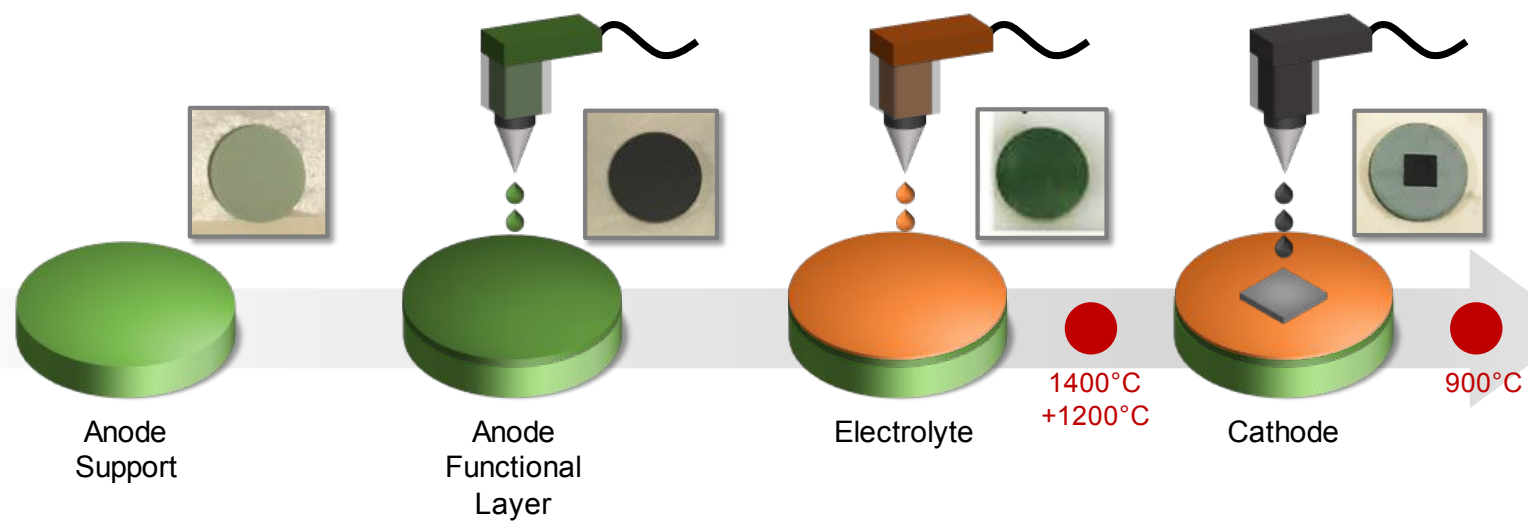

Figure S1. Schematic of the thin-film SOFC fabrication process using the inkjet printing method with optical images of an actual sample corresponding to each step. 


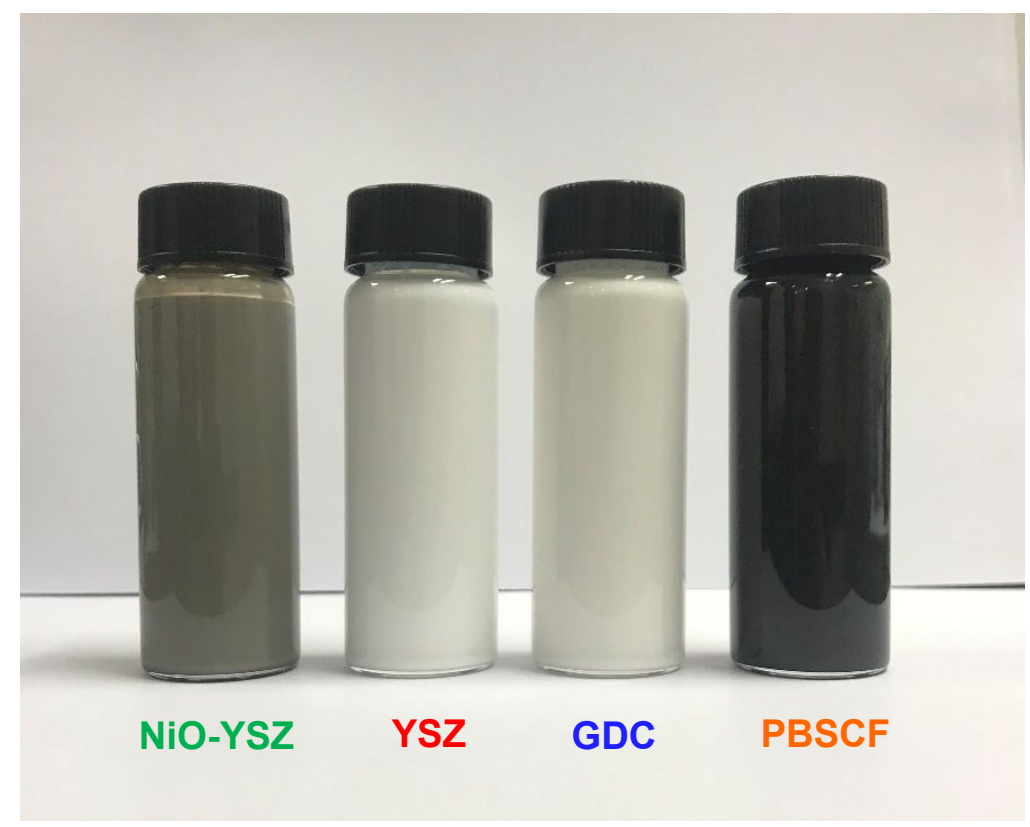

Figure S2. Photograph of the synthesized NiO-YSZ, YSZ, GDC, and PBSCF inks. 


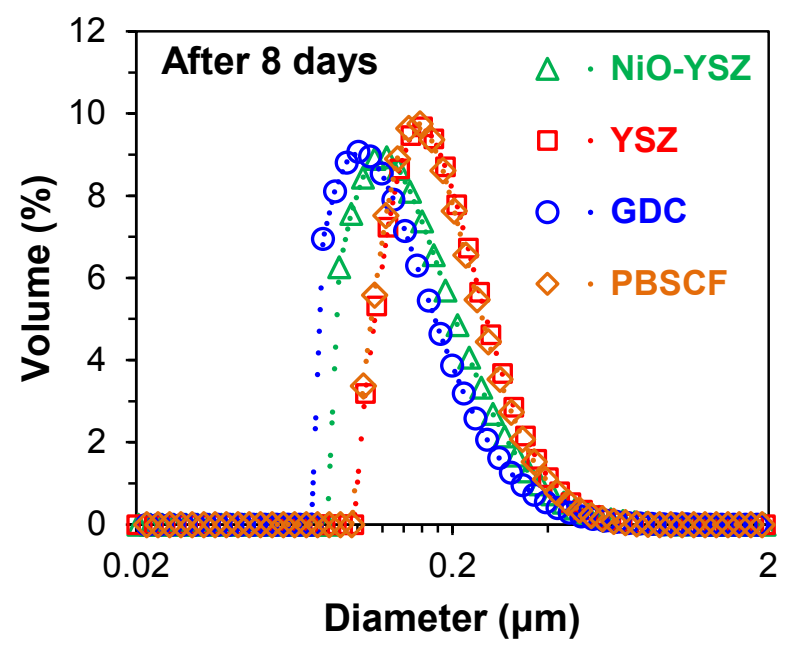

Figure S3. Properties of the NiO-YSZ, YSZ, GDC, and PBSCF inks. Particle size distributions analyzed on the $8^{\text {th }}$ day after the synthesis. 


\section{Fluidic properties of the ceramic inks}

The viscosities and surface tensions were measured to evaluate the physical properties of the ceramic ink fluids. The viscosity is related mainly to the ink flow rate inside the printhead. ${ }^{3}$ Figure S4a shows that the viscosities of the analyzed NiO-YSZ, YSZ, GDC, and PBSCF ceramic inks are 3.1, 4.7, 4.8, and 3.6 cP, respectively. The relatively high solid fractions of the YSZ and GDC inks contribute to their high viscosities, compared with the other inks. ${ }^{3}$ The surface tension is associated mainly to the optimal drop shape formation. ${ }^{4}$ Figure S4b shows the surface tensions of the ceramic inks compared with that of the commercially available HP63 ink. The NiO-YSZ, YSZ, and GDC inks have surface tensions similar to that of the HP63 ink. For the YSZ ink, the slightly low surface tension of $32.5 \mathrm{mN} \mathrm{m}^{-1}$ is attributed to the relatively high mass ratio of ethanol in the solvent mixture (water:ethanol $=2: 1 \mathrm{w}: \mathrm{w}$ ). The surface tensions of the pure water and ethanol are 72.8 and $22.3 \mathrm{mN} \mathrm{m}^{-1}$ at $20^{\circ} \mathrm{C}$, respectively. ${ }^{5,6}$ In contrast, the PBSCF ink exhibits the lowest surface tension of $26.3 \mathrm{mN} \mathrm{m}^{-1}$, as the PGME organic solvent (surface tension: $27.7 \mathrm{mN}$ $\mathrm{m}^{-1}$ at $23{ }^{\circ} \mathrm{C}$ ) corresponds to a large portion of the solvent mixture instead of distilled water (Figure S4b). Unlike the NiO-YSZ, YSZ, and GDC inks, which are water-based inks, the PBSCF ink is fully based on organic solvents, considering the reactivities of alkaline earth metals $(\mathrm{Ba}, \mathrm{Sr})$ with water. Considering the general use of aqueous inks in thermal inkjet printers, the PBSCF ink is obtained from organic solvents with fluid properties suitable for inkjet printing. 

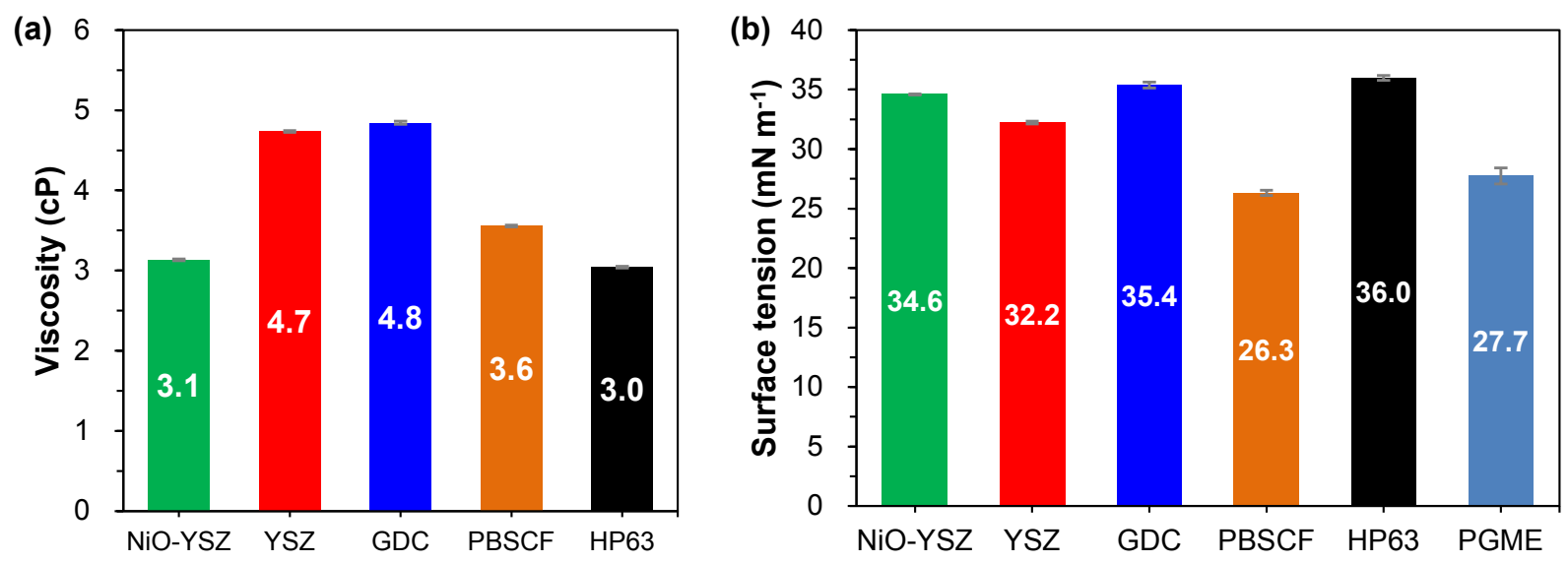

Figure S4. Fluid properties of the NiO-YSZ, YSZ, GDC, and PBSCF inks. (a) Viscosities of the ceramic inks analyzed using a vibrational viscometer. (b) Surface tensions of the ceramic inks analyzed using a ring-type surface tensiometer. For comparison with the ceramic inks, the fluid properties of the HP63 ink and PGME solvent were also analyzed. 

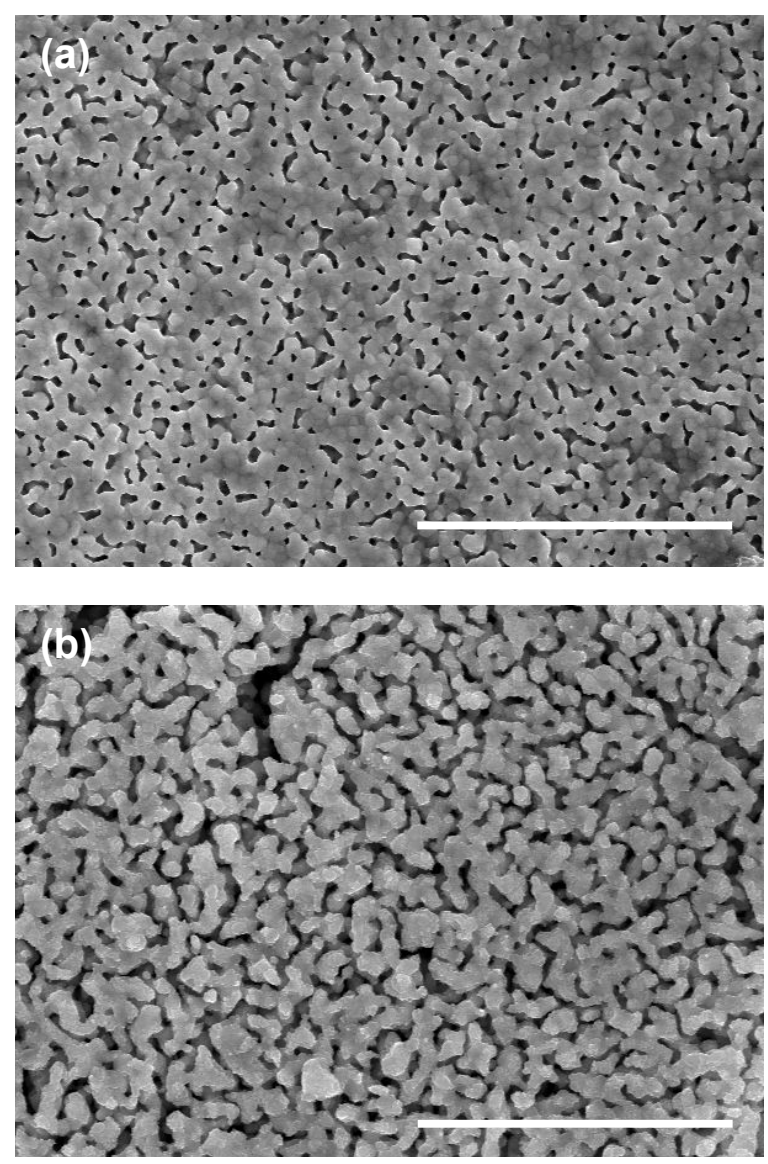

Figure S5. Microstructures of the inkjet-printed SOFC. (a) Surface morphologies of the GDC buffer layer and (b) PBSCF cathode layer visualized by SEM (scale bars: 10 and $5 \mu \mathrm{m}$, respectively). 

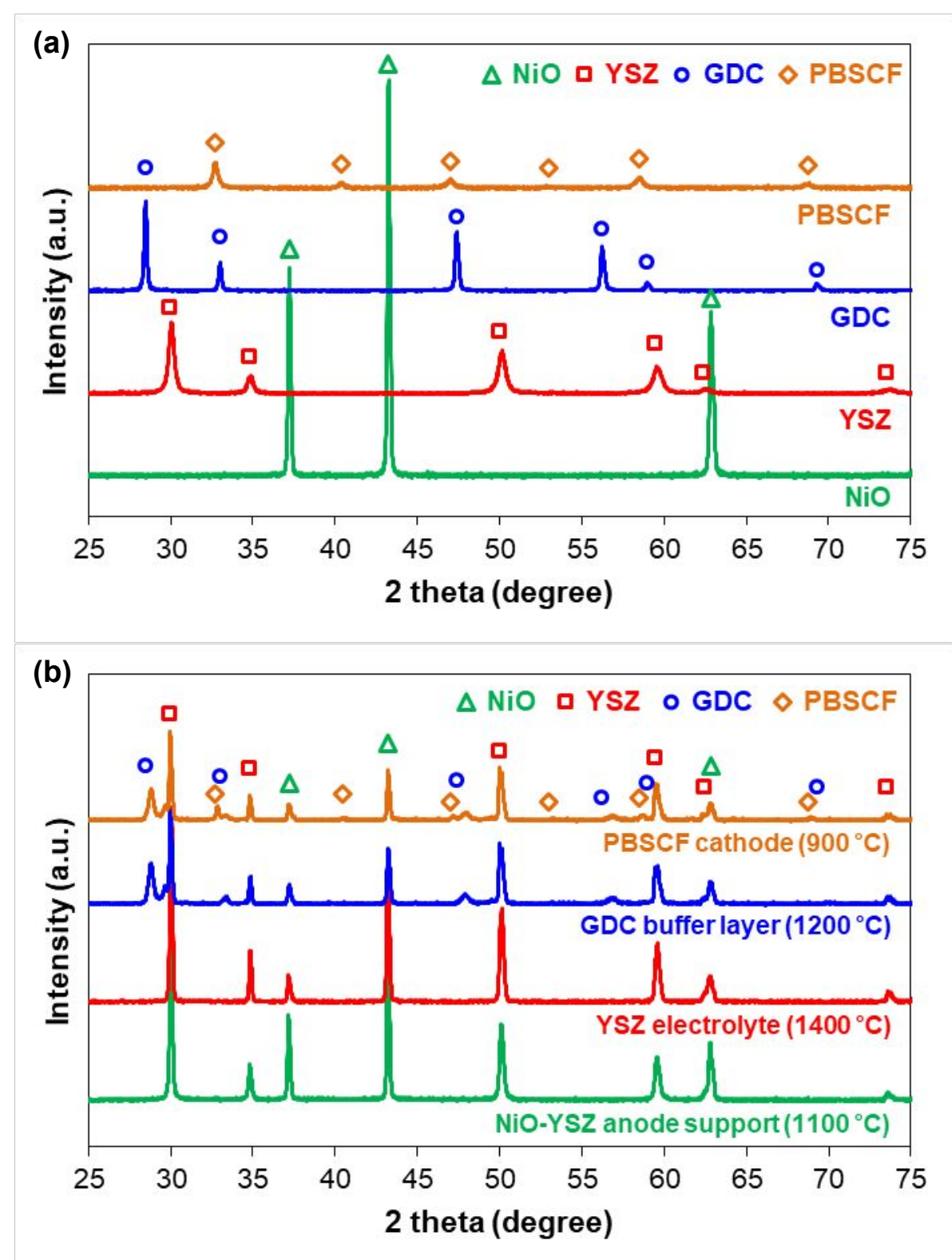

Figure S6. XRD patterns of the raw ceramic powders and inkjet-printed SOFC composed of NiO-YSZ | YSZ | GDC | PBSCF. (a) XRD patterns of the raw ceramic powders used to fabricate the inkjet-printed SOFC. (b) XRD pattern at each sintering step of the inkjet-printed SOFC. The $\mathrm{NiO}-\mathrm{YSZ}$ anode support was fired at $1100^{\circ} \mathrm{C}$ for $3 \mathrm{~h}$, the $\mathrm{YSZ}$ electrolyte was deposited on the NiO-YSZ AFL and cosintered at $1400{ }^{\circ} \mathrm{C}$ for $2 \mathrm{~h}$, the GDC buffer layer was deposited on the YSZ electrolyte and then sintered at $1200^{\circ} \mathrm{C}$ for $2 \mathrm{~h}$, and the PBSCF cathode layer was sintered at $900{ }^{\circ} \mathrm{C}$ for $3 \mathrm{~h}$. 

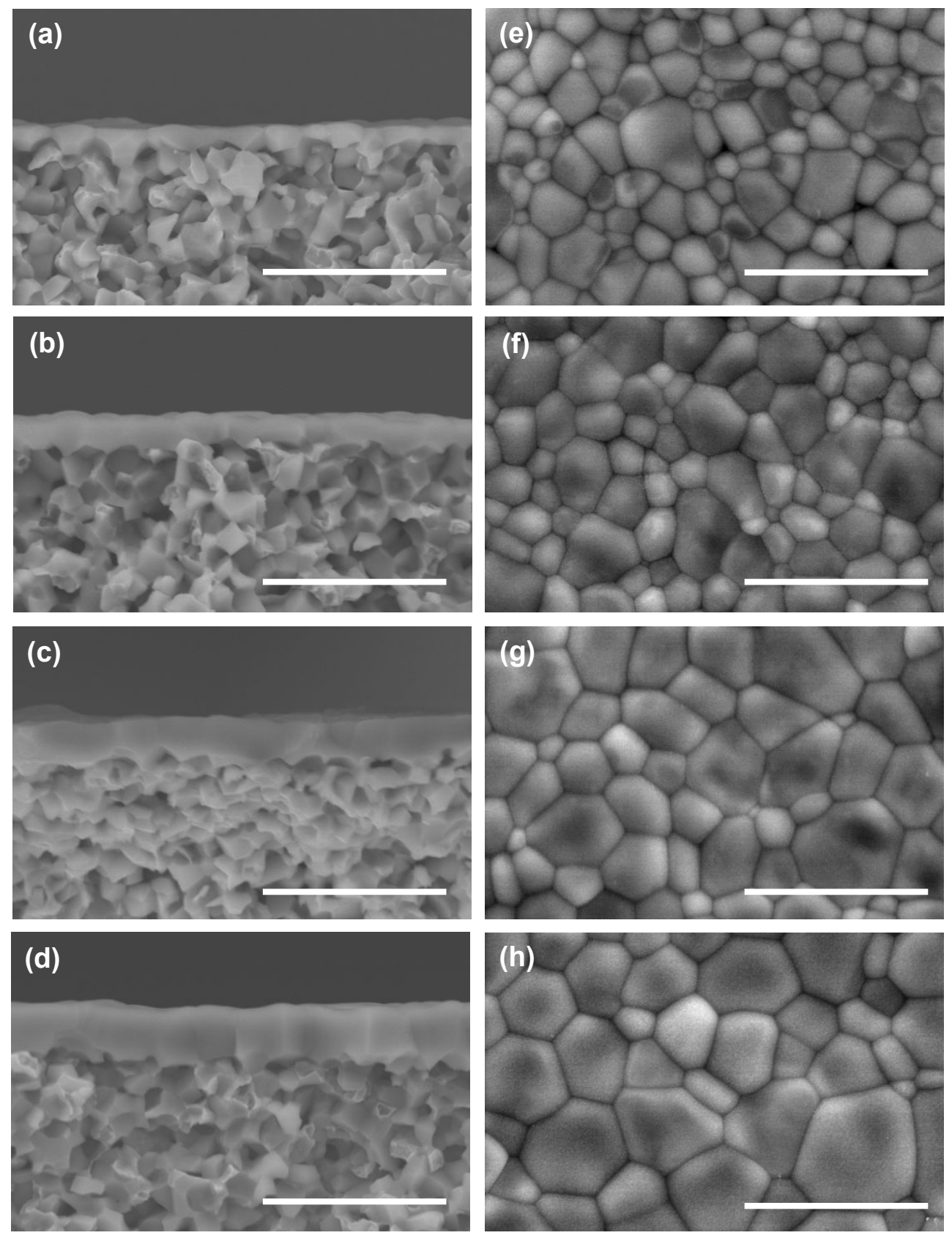

Figure S7. Microstructures of the inkjet-printed SOFCs with different electrolyte thicknesses. (a-d) Cross-sectional and (e-h) surface SEM images of the YSZ electrolytes formed on the NiO-YSZ AFLs after (a, e) 1, (b, f) 2, (c, g) 3, and (d, h) 4 printing scan cycles, respectively (scale bar: $5 \mu \mathrm{m}$ ). 

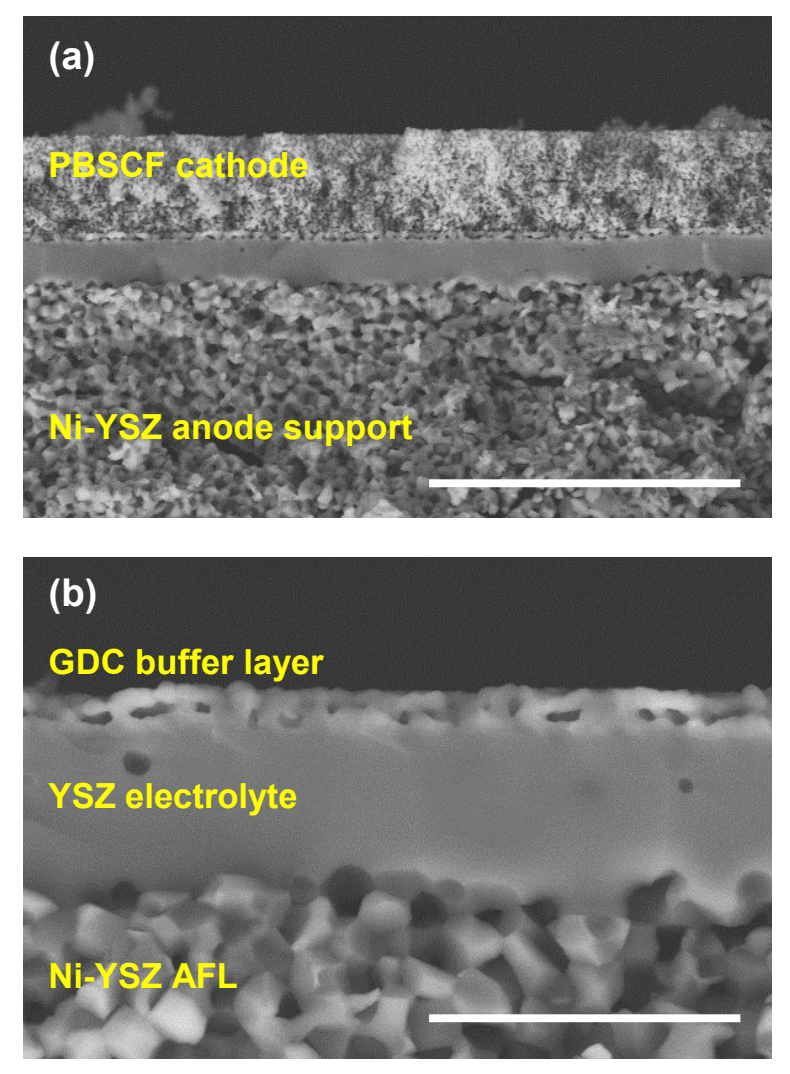

Figure S8. Microstructures of the inkjet-printed SOFC. (a) Cross-sectional SEM image of the SOFC with the $2.4 \mu \mathrm{m}$ thick YSZ electrolyte (scale bar: $20 \mu \mathrm{m}$ ). (b) High-magnification SEM image of the SOFC with the $2.4 \mu \mathrm{m}$ thick YSZ electrolyte (scale bar: $5 \mu \mathrm{m}$ ). 

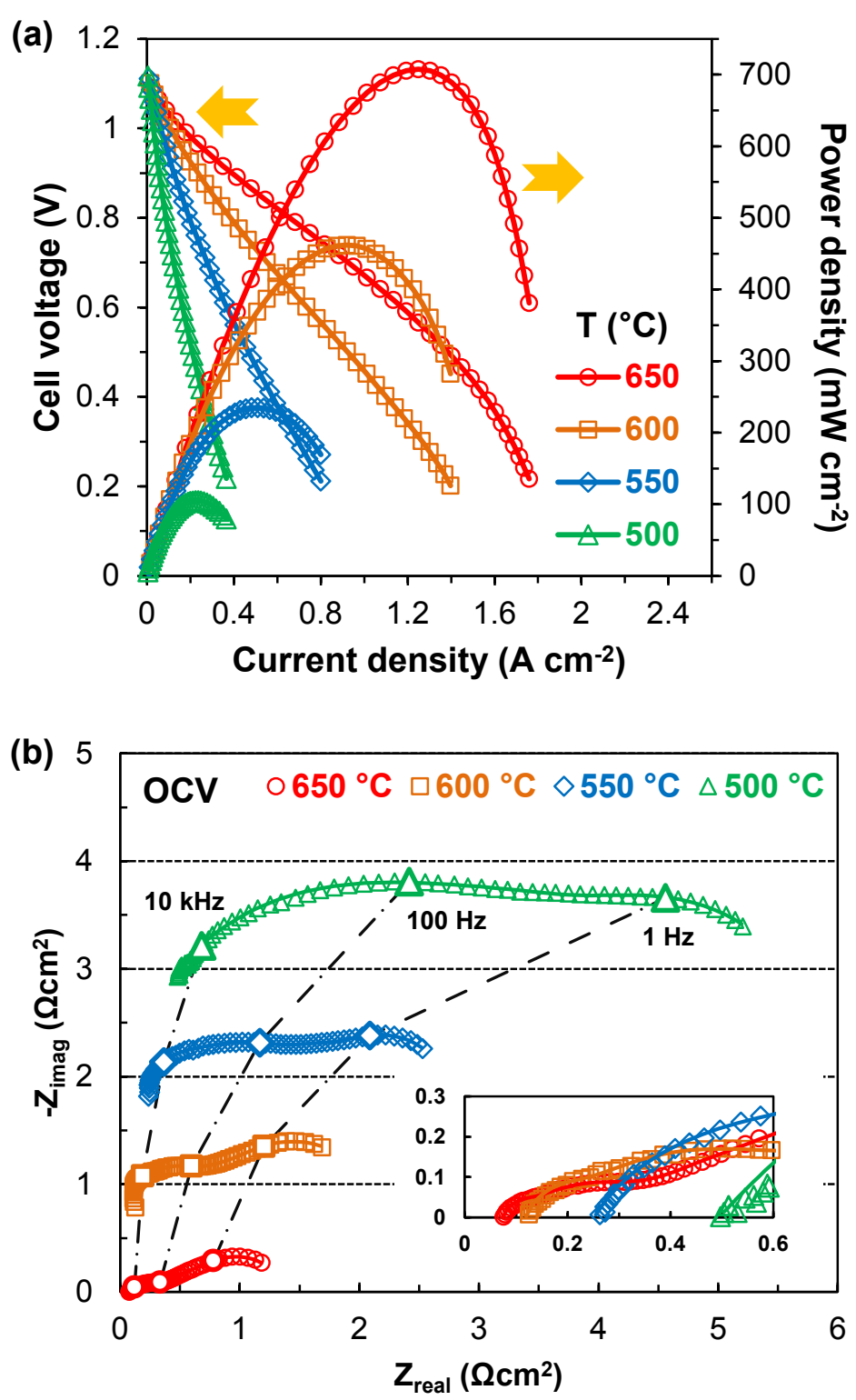

Figure S9. Electrochemical performances of the inkjet-printed SOFC. (a) $I-V$ curves and (b) EIS data of the SOFC with the $2.4 \mu \mathrm{m}$ thick YSZ electrolyte (5 printing scan cycles) in the range of 500-650 ${ }^{\circ} \mathrm{C}$. 
EIS.

An EIS analysis of the inkjet-printed SOFCs with the 0.8 and $2.4 \mu \mathrm{m}$ thick YSZ electrolytes was performed. Figure $6 \mathrm{~b}$ and Figure $\mathrm{S} 9 \mathrm{~b}$ show the Nyquist plots for each sample, measured under OCVs at $650,600,550$, and $500{ }^{\circ} \mathrm{C}$. An equivalent circuit with one resistance and four resistances/constant-phase elements (CPEs) was used to fit the measured EIS data. The sum of the resistances in the four resistance/CPEs indicates the area-specific polarization resistance $\left(\mathrm{ASR}_{\mathrm{pol}}\right)$, while the one resistance is the area-specific ohmic resistance $\left(\mathrm{ASR}_{\mathrm{ohm}}\right)$. Figure $\mathrm{S} 10$ shows Arrhenius plots for each sample, measured under a cell voltage of $0.75 \mathrm{~V}$. The decrease in $\mathrm{ASR}_{\text {ohmic }}$ for the SOFC with the $0.8 \mu \mathrm{m}$ thick YSZ electrolyte indicates the effect of the electrolyte thickness reduction. 


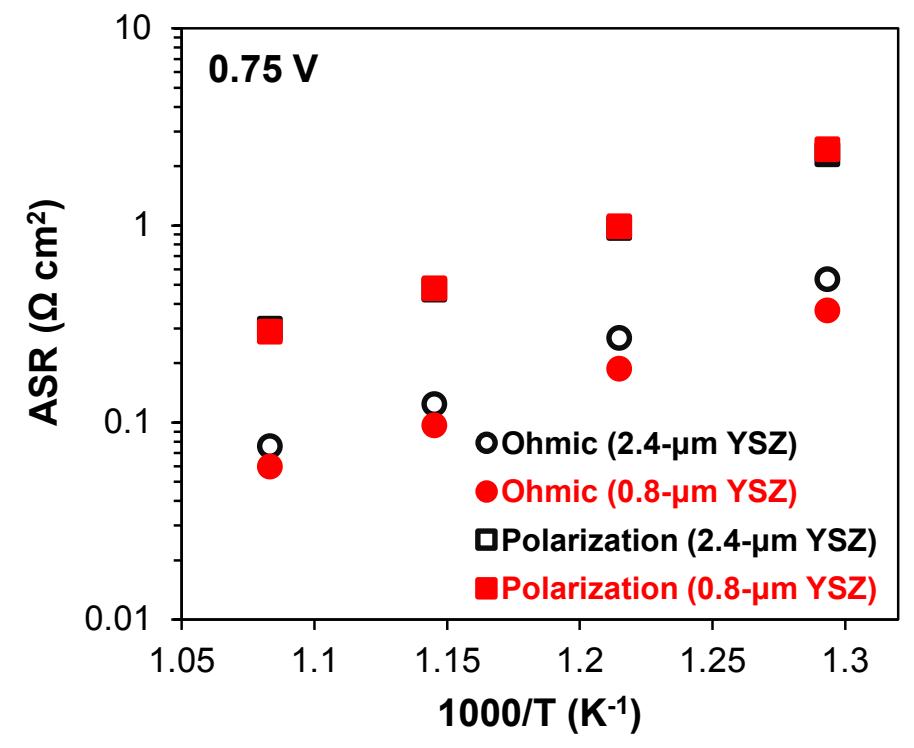

Figure S10. Arrhenius plots $\left(\mathrm{ASR}_{\mathrm{pol}}\right.$ and $\left.\mathrm{ASR}_{\mathrm{ohm}}\right)$ of the inkjet-printed SOFCs with the 0.8 and $2.4 \mu \mathrm{m}$ thick YSZ electrolytes, measured in the range of $500-650{ }^{\circ} \mathrm{C}$. The electrochemical impedance analysis was carried out at a cell voltage of $0.75 \mathrm{~V}$. 


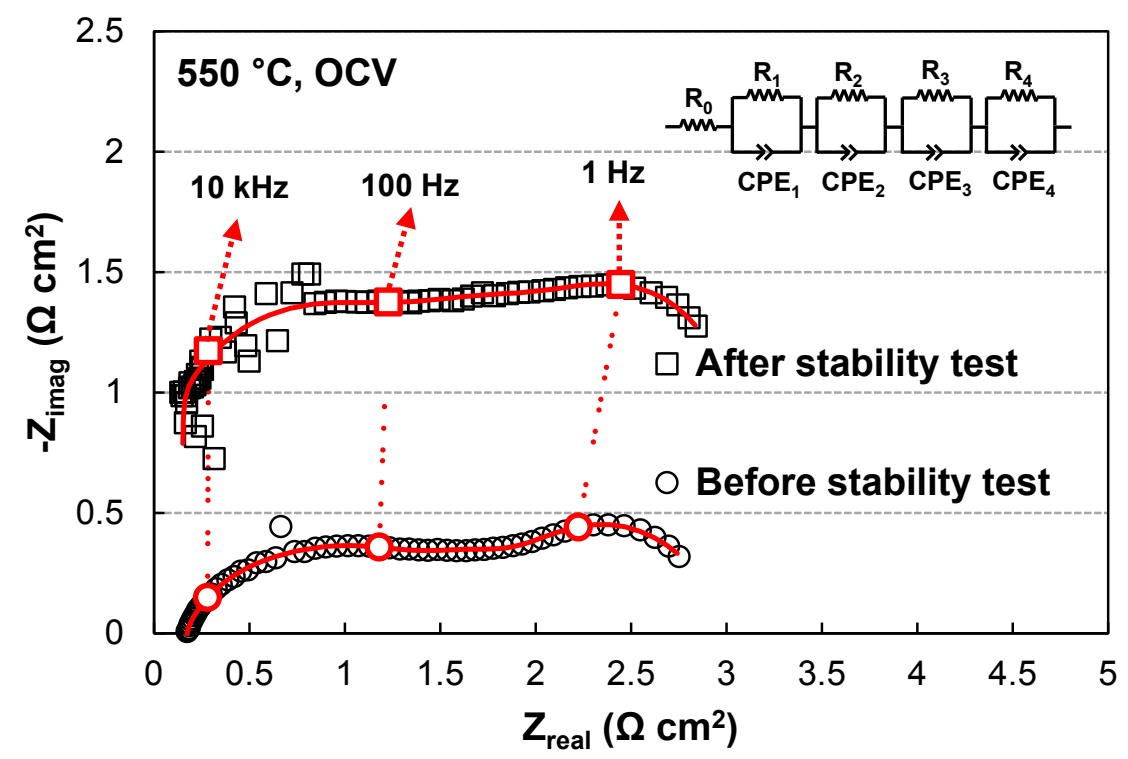

Figure S11. EIS results of the inkjet-printed SOFC with the $0.8 \mu \mathrm{m}$ thick YSZ electrolyte measured at $550{ }^{\circ} \mathrm{C}$. Comparison of the EIS data measured at the OCV before and after the stability test over $110 \mathrm{~h}$. The inset is the equivalent circuit for fitting of the EIS data. 

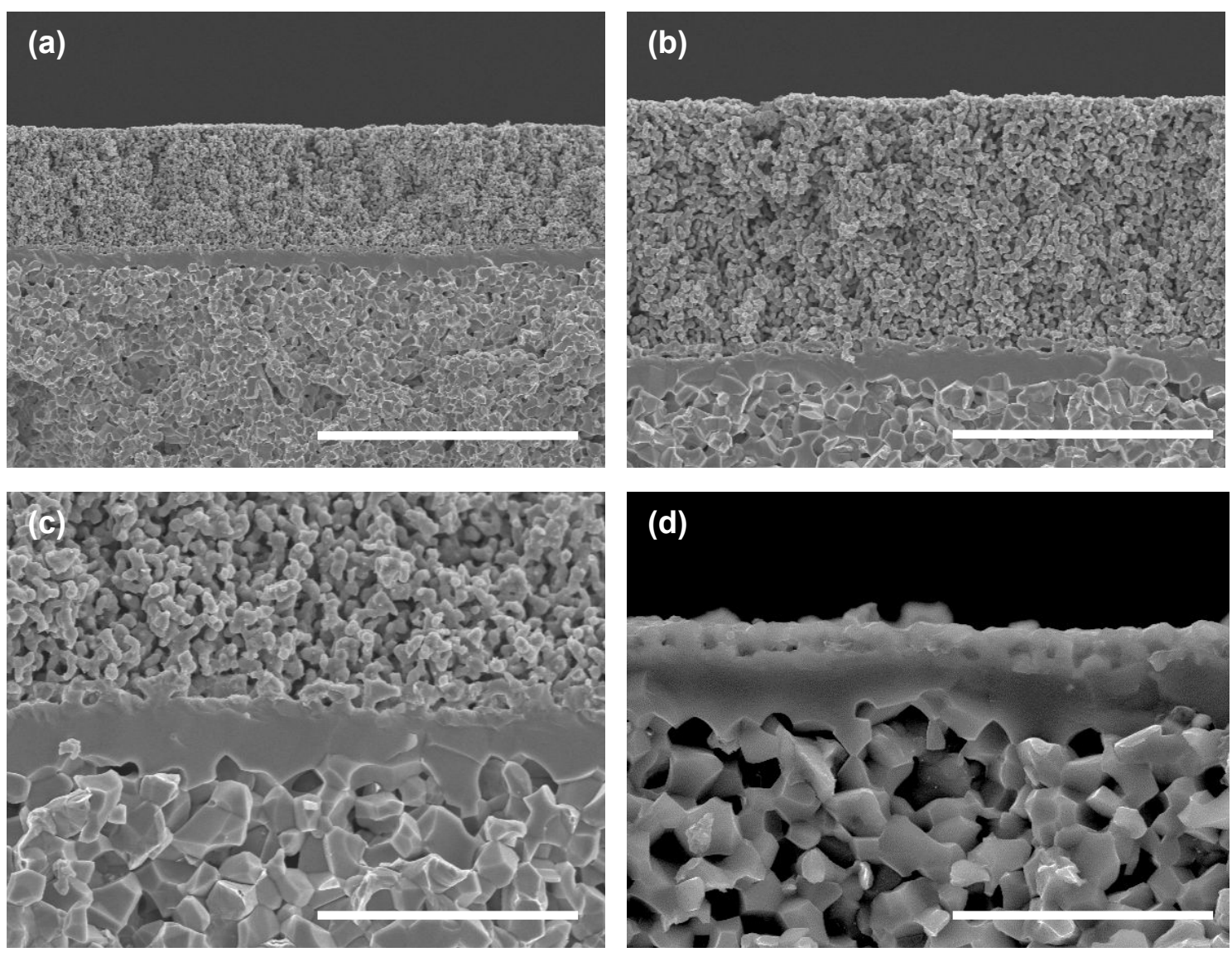

Figure S12. Microstructures of the inkjet-printed SOFC with the $0.8 \mu \mathrm{m}$ thick YSZ electrolyte observed after the long-term stability test. (a-c) Cross-sectional SEM images of the inkjetprinted SOFC at different magnifications (scale bars: 20, 10, and $5 \mu \mathrm{m}$, respectively). (d) Crosssectional SEM image of the SOFC at locations without the PBSCF cathode layer (scale bar: 5 $\mu \mathrm{m})$. 


\section{Supplementary References}

(1) Jung, H. Y.; Choi, S.-H.; Kim, H.; Son, J.-W.; Kim, J.; Lee, H.-W.; Lee, J.-H. Fabrication and Performance Evaluation of 3-Cell SOFC Stack Based on Planar $10 \mathrm{~cm} \times 10 \mathrm{~cm}$ AnodeSupported Cells. J. Power Sources 2006, 159(1), 478-483.

(2) Noh, H.-S.; Lee, H.; Kim, B.-K.; Lee, H.-W.; Lee, J.-H.; Son, J.-W. Microstructural Factors of Electrodes Affecting the Performance of anode-Supported Thin Film Yttria-Stabilized Zirconia Electrolyte $(\sim 1 \mu \mathrm{m})$ Solid Oxide Fuel Cells. J. Power Sources 2011, 196(17), 7169-7174.

(3) Zapka, W. Handbook of Industrial Inkjet Printing: A Full System Approach, John Wiley \& Sons, New Jersey, 2017.

(4) Hill, T. Y.; Reitz, T. L.; Rottmayer, M. A.; Huang, H. Controlling inkjet fluid kinematics to achieve SOFC cathode micropatterns. ECS J. Solid-State Sci. Technol. 2015, 4, P3015-P3019.

(5) Pallas, N. R.; Harrison, Y. An automated drop shape apparatus and the surface tension of pure water. Colloids Surf. 1990, 43, 169-194.

(6) Vazquez, G.; Alvarez, E; Navaza, J. M. Surface tension of alcohol + water from 20 to $50{ }^{\circ} \mathrm{C}$. J. Chem. Eng. Data 1995, 40, 611-614. 